\title{
CONSTRUÇÃO E APLICAÇÃO DE UMA CELA ESPECTROFOTOMÉTRICA DE CAMADA DELGADA PARA ANÁLISES EM FLUXO
}

Paulo C. C. de Oliveira, Vitor J. P. Gouveia e Jorge C. Masini*

Instituto de Química, Universidade de São Paulo, CP 26077, 05513-970 São Paulo - SP

Recebido em 12/4/00; aceito em 6/9/00

CONSTRUCTION AND APPLICATION OF A THIN LAYER SPECTROPHOTOMETRIC CELL FOR FLOW ANALYSIS. A low cost spectrophotometric cell for use in flow analysis was manufactured in acrylic and adapted to a commercial spectrophotometer. The application of this cell was performed in the determination of chromium (VI) in steel samples using the reaction with the alkaloid brucine in presence of oxalic acid and $0.6 \mathrm{~mol} \mathrm{~L}^{-1}$ sulfuric acid. The cell allows an enlarged analytical range, diminishing the extension of dilutions, which is useful for on-line monitoring of industrial processes.

Keywords: thin layer cell; spectrophotometric $\mathrm{Cr}(\mathrm{VI})$ determination; steel samples.

\section{INTRODUÇÃO}

Devido ao fato das celas espectrofotométricas para análise em fluxo ainda apresentarem preços relativamente elevados, a construção e uso de celas artesanais que conciliem baixo custo e bom desempenho tem sido bastante descrito na literatura ${ }^{1-6}$. Um dos principais problemas encontrados nas celas, sejam comerciais ou não, é a retenção de bolhas no percurso óptico. Para contornar este inconveniente, as celas comerciais adotam várias geometrias como celas em forma de "U", "Z" e com um aprisionador de bolha em forma de "J" antes do percurso óptico. Dentre as três configurações acima citadas, a que apresenta maior necessidade de intervenções devido ao aprisionamento de bolhas de ar durante as análises é a cela espectrofotométrica em forma de "U".

Reis ${ }^{1}$ construiu uma cela espectrofotométrica de baixo custo, constituida de três blocos de Perspex ${ }^{\mathrm{MR}}$ agrupadas em forma de sanduíche. Apesar de sua construção simples, a cela possui percurso óptico fixo e requer intervenção do operador para remoção de bolhas de ar.

Araújo et al. ${ }^{2}$ desenvolveram um modelo de cela espectrofotométrica, inserindo um tubo de vidro $(4,5 \mathrm{~cm}$ de comprimento e $2 \mathrm{~mm}$ de diâmetro interno) verticalmente dentro de um suporte de madeira com uma fenda retangular com dimensões $2 \times 5 \mathrm{~mm}$ para a passagem do feixe óptico. Esta configuração elimina a possibilidade de retenção de bolhas pois o fluxo ascendente arrasta as bolhas. Porém, o volume morto tornase relativamente grande e a sensibilidade comprometida.

Pasquini e Raimundo $\mathrm{Jr}^{3}{ }^{3}$ descrevem a construção de um fotômetro simples para análise por injeção em fluxo e adaptam uma cela de fluxo em U, cujo percurso óptico é fixo e requer intervenção para retirada de bolhas.

Um modelo mais versátil foi confeccionada por Pavón et al. ${ }^{4}$. Esta cela é composta por dois blocos de PVC e utiliza separadores em Teflon ${ }^{\mathrm{MR}}$. As análises são realizadas pela medida da reflectância da luz captada através de cabos de fibra óptica. Suas vantagens residem no pequeno volume interno, facilidade de variar o percurso óptico, não retenção de bolhas, podendo ainda ser utilizada como cela de difusão de gases. Sua desvantagem está no elevado custo das fibras ópticas, além da necessidade de um espectrofotômetro apropriado para o seu emprego.

Uma cela para medidas espectrofotométricas em fase sólida foi construída por Reis e colaboradores ${ }^{5}$. Esta cela é composta

e-mail: jcmasini@quim.iq.usp.br por dois blocos de acrílico separados por uma borracha de 1,0 $\mathrm{mm}$ de espessura na qual é feito um orifício de $10 \mathrm{~mm}$ de diâmetro. Este corte circular fixa a fase estacionária constituida de 1-(2-tiazolilazo)-2-naftol (TAN) imobilizado em sílica funcionalizada $\mathrm{C}_{18}$. Com a detecção espectrofotométrica em fase sólida, incorpora-se uma etapa de preconcentração, resultando em considerável ganho de sensibilidade quando comparado com sistemas convencionais. Um dos pontos críticos desta cela é o fato de sua geometria causar uma distribuição heterogênea do analito, em virtude da ocorrência de caminhos preferenciais da solução contendo o analito. Para contornar este problema, um estudo do posicionamento da distância da cela em relação ao feixe óptico é crucial ${ }^{5}$.

Uma cela espectroeletroquímica foi confeccionada por Gouveia et al. ${ }^{6}$ com volume interno de aproximadamente $20 \mu \mathrm{L}$ para detecção de $\mathrm{Fe}(\mathrm{II})$ através do efeito de espalhamento de radiação (Raman).

No presente trabalho, construiu-se uma cela delgada com fluxo vertical e adaptou-se a um espectrofotometro comercial. Para exemplificar sua utilização e verificar seu desempenho, determinou-se íons $\mathrm{Cr}(\mathrm{VI})$ em amostras de aço certificadas através de análise por injeção seqüencial.

A análise por injeção seqüencial foi desenvolvida em 1990 por Ruzicka e Marshall ${ }^{7}$ como uma modalidade de técnica de fluxo apropriada para monitorização de processos industriais em função de suas características: robustez mecânica, baixa necessidade de manutenção, pequeno consumo de reagentes e solução transportadora, maior autonomia, entre outros. $\mathrm{O}$ sistema de injeção seqüencial é composto de um seringa de pistão responsável pela aspiração ou injeção de volumes precisos de tranportador e reagentes. O coração do sistema é uma válvula seletora com 8 portas comunicáveis através de uma porta comum. Todo o sistema é controlado automaticamente por um computador, garantindo maior autonomia para o sistema.

A determinação de cromo é de grande relevância tanto do ponto de vista ambiental quanto industrial. Muito embora o cromo no estado de oxidação trivalente seja um elemento essencial, atuando como regulador do metabolismo da glicose, no estado de oxidação hexavalente possui elevada toxicidade, sendo apontado na literatura como causador de dermatites, problemas no trato respiratório e intestinal, além de potencialmente carcinogênico ${ }^{8}$.

Em virtude de seu elevado potencial de toxicidade, o desenvolvimento de metodologias de análise com características de tempo real são de grande importância na quantificação deste analito. 
A determinação de $\mathrm{Cr}$ (VI) baseou-se no aproveitamento analítico do intermediário formado na reação entre $\mathrm{Cr}(\mathrm{VI})$ e o alcalóide brucina ${ }^{9}$. O intermediário formado absorve fortemente em $525 \mathrm{~nm}$ e após alguns segundos, converte-se no produto final, que absorve mais fracamente em $430 \mathrm{~nm}$. Com o aproveitamento analítico do estado transiente (intermediário), menor tempo de análise e maior sensibilidade na determinação de Cr(VI) são verificados, sendo somente possível sua detecção através de técnicas de fluxo.

\section{EXPERIMENTAL}

\section{A Cela Delgada de Fluxo Vertical}

A cela espectrofotométrica consiste simplesmente de dois blocos de acrílico de dimensões $42 \mathrm{~mm}$ de altura por $13 \mathrm{~mm}$ de largura e $6 \mathrm{~mm}$ de espessura, contendo em um deles dois pequenos furos de $2 \mathrm{~mm}$ de diâmetro para entrada e saída de solução dispostos verticalmente e distantes entre si por 18 $\mathrm{mm}$. Nos dois blocos efetuou-se dois furos concêntricos de 8 $\mathrm{mm}$ e $4 \mathrm{~mm}$ de diâmetro respectivamente. $\mathrm{O}$ furo menor (4 $\mathrm{mm}$ ) atravessa todo o acrílico nas duas peças e o de $8 \mathrm{~mm}$ não chega a atravessar as placas de acrílico, servindo apenas de apoio para a fixação das janelas de vidro. As placas de acrílico são separadas por um espaçador de borracha removível com espessuras que variam de 0,6 a $0,8 \mathrm{~mm}$, que regulam o volume interno e o caminho óptico da cela. $O$ volume interno da cela é de aproximadamente $31 \mu \mathrm{L}$ quando a espessura da borracha de separação é $0,6 \mathrm{~mm}$. O desenho detalhado da cela é mostrado na Figura 1.
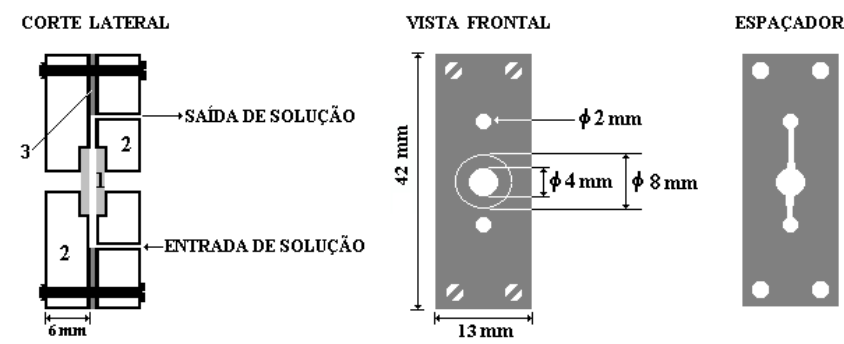

\footnotetext{
1 - JANELAS DE VIDRO

2 - CORPO DE ACRIIIICO

3 - ESPAÇADOR (0,6 mm)
}

Figura 1. Desenho da cela delgada de fluxo vertical.

\section{Reagentes e Soluções}

Todos os reagentes são de grau de pureza analítica e todas as soluções foram preparadas com água desionizada (NANO pure water system).

A solução estoque de tampão borato $0,10 \mathrm{~mol} \mathrm{~L}^{-1}$ foi preparada pela pesagem de $38,143 \mathrm{~g}$ de $\mathrm{Na}_{2} \mathrm{~B}_{4} \mathrm{O}_{7} .10 \mathrm{H}_{2} \mathrm{O}$ seguido de sua dissolução com água em balão volumétrico de $1 \mathrm{~L}$. A solução estoque de azul de bromotimol (BTB) $0,01 \%(\mathrm{~m} / \mathrm{v})$ foi preparada pela pesagem de $0,01 \mathrm{~g}$ do corante e dissolvido em $100 \mathrm{~mL}$ de tampão borato $0,01 \mathrm{~mol} \mathrm{~L}^{-1}$. Para preparação da solução de brucina (Aldrich), pesou-se 0,22 g de brucina acrescidos de 0,95 g de ácido oxálico (Merck) e $10 \mathrm{~mL}$ de ácido sulfúrico (Merck) $6 \mathrm{~mol} \mathrm{~L}^{-1}$, seguidos de dissolução com água para volume final de $100 \mathrm{~mL}$ em balão volumétrico. Solução padrão estoque de $\mathrm{Cr}(\mathrm{VI}) 100 \mathrm{mg} \mathrm{L}^{-1}$ : pesou-se $0,2829 \mathrm{~g}$ de $\mathrm{K}_{2} \mathrm{Cr}_{2} \mathrm{O}_{7}$ (Merck), previamente dessecado em estufa a $140{ }^{\circ} \mathrm{C}$ por uma hora, dissolvidos em $1 \mathrm{~L}$ de água desionizada. As soluções de trabalho foram preparadas por diluição adequada a partir da solução estoque.

\section{Equipamentos}

Utilizou-se um sistema de injeção seqüencial modelo FIAlab 3500 (Alitea USA, Medina, WA, USA), esquematizado na Figura 2. A detecção foi realizada com um espectrofotômetro Micronal Modelo B 382 acoplado a um registrador Micronal modelo B 292 ou através de placa de aquisição de dados PCLPM 16 da National Instruments.

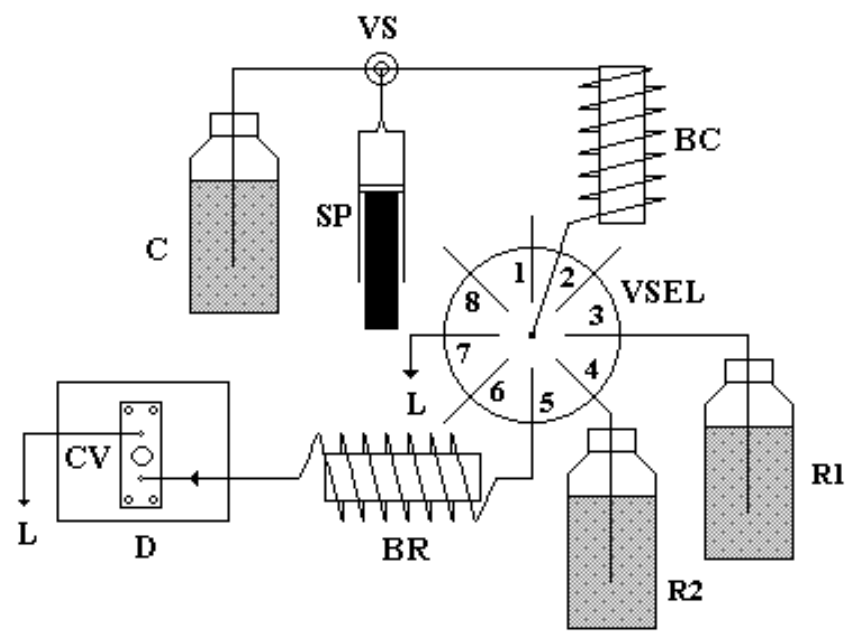

Figura 2. Sistema de injeção seqüencial. $\boldsymbol{C}=$ solução transportadora; $\boldsymbol{V S}=$ válvula da seringa $; \boldsymbol{S P}=$ seringa de pistão; $\boldsymbol{B C}=$ bobina coletora (i.d. 0,8mm; comp. $200 \mathrm{~cm}) ; \boldsymbol{V S E L}=$ válvula seletora; $\boldsymbol{L}=$ descarte de lavagem ou de análise $; \boldsymbol{R} \mathbf{I}=$ reagente colorimétrico; $\boldsymbol{R} \mathbf{2}=$ padrão ou amostra; $\boldsymbol{B} \boldsymbol{R}=$ bobina de reação (i.d. $0,5 \mathrm{~mm} ;$ comp. $100 \mathrm{~cm}) ; \boldsymbol{D}=$ detector $\boldsymbol{e} \boldsymbol{C} \boldsymbol{V}=$ cela vertical

\section{Preparação das amostras}

Pesou-se $0,20 \mathrm{~g}( \pm 0,1 \mathrm{mg})$ de amostra de aço, transferiu-se para um bequer de $200 \mathrm{~mL}$ e adicionou-se $20 \mathrm{~mL}$ de água régia. Aqueceu-se em chapa de aquecimento até completa dissolução do sólido. Em seguida, adicionou-se $10 \mathrm{~mL}$ de ácido perclórico concentrado para eliminar os produtos de decomposição do ácido nítrico e oxidar o $\mathrm{Cr}$ (III) . O aquecimento continuou até que os fumos brancos do ácido perclórico fossem liberados (próximo à secura) e os sais precipitassem.

Após o aquecimento, esperou-se esfriar à temperatura ambiente e diluiu-se com $20 \mathrm{~mL}$ de água desionizada. Filtrou-se em funil de vidro, utilizando papel de filtro Wattman 42, recolhendo-se o filtrado diretamente em balão volumétrico de 100 mL. Lavou-se o resíduo com várias porções de água desionizada, completou-se o volume dos balões com água desionizada até o menisco e transferiu-se seu conteúdo para frascos de estocagem devidamente limpos e secos.

Procedeu-se a determinação espectrofotométrica do cromo através do uso analítico do intermediário formado na sua reação com a brucina.

\section{Procedimento de análise através do sistema de Injeção Seqüencial}

As etapas realizadas nas calibrações e análises de $\mathrm{Cr}(\mathrm{VI})$ através de Injeção Seqüencial são resumidas na Tabela 1, tendo como base o sistema mostrado na Figura 2. O procedimento descrito é iniciado após todo o sistema de tubos estar preenchido com solução transportadora (água desionizada para análise de íons $\mathrm{Cr}(\mathrm{VI})$ e tampão borato para os testes de desempenho da cela). O tubo ligado à porta 3 da válvula seletora estar preenchido com o reagente colorimétrico. No estudo sobre o desempenho da cela com BTB o procedimento é similar, mas a etapa 9 é suprimida, uma vez que não há reação química envolvida. 
Tabela 1. Etapas executadas no sistema de injeção seqüencial para análise das amostras reais.

\begin{tabular}{clc}
\hline Etapa & Descrição & Vazão $\left(\mu \mathrm{L} \mathrm{s} \mathrm{s}^{-1}\right)$ \\
\hline 1 & Válvula da seringa conecta seringa com frasco de solução transportadora & - \\
2 & Aspira-se 1,0 ml de solução transportadora para dentro da seringa & 200 \\
3 & Válvula da seringa conecta seringa com a válvula seletora & - \\
4 & Posiciona-se a válvula seletora na porta 4 e aspira-se 200 $\mu \mathrm{L}$ de padrão/amostra para a bobina coletora & 100 \\
5 & Posiciona-se a válvula seletora na porta 7 e esvazia-se a seringa & 200 \\
6 & Válvula da seringa conecta seringa com frasco de solução transportadora & - \\
7 & Aspira-se 2,5 ml de solução transportadora para dentro da seringa & 200 \\
8 & Válvula da seringa conecta seringa com a válvula seletora & - \\
9 & Posiciona-se a válvula seletora na porta 3 e aspira-se 200 $\mu \mathrm{L}$ de regente colorimétrico para a bobina coletora & 100 \\
10 & Posiciona-se a válvula seletora na porta 4 e aspira-se 100 $\mu \mathrm{L}$ de amostra/padrão para a bobina coletora & 100 \\
11 & Posiciona-se a válvula seletora na porta 5 e esvazia-se a seringa através da bobina de reação e detector & 100 \\
\hline
\end{tabular}

As etapas de 1 a 5 são necessárias para preencher o canal entre o frasco de amostra e/ou padrão e a válvula seletora com a solução a ser analizada. As etapas 6 a 11 referem-se ao procedimento de análise propriamente dito.

\section{RESULTADOS E DISCUSSÃO}

\section{Desempenho da Cela Delgada de Fluxo Vertical}

Estudos comparativos entre a cela construída e uma cela de fluxo comercial em forma de "U" com percurso óptico de $10 \mathrm{~mm}$ foram executados. Registrou-se sinais de soluções de azul de bromotimol (BTB) a $620 \mathrm{~nm}$, com concentrações variando de $1,0.10^{-4} \%$ a $1,0.10^{-2} \%(\mathrm{~m} / \mathrm{v})$.

Os parâmetros analíticos das curvas obtidas com ambas celas e para as amostras reais são resumidos na Tabela 2 , indicando que com a cela delgada as absorbâncias na altura máxima de pico apresentam uma relação linear para toda a faixa de concentrações estudada. Com a cela comercial as concentrações restringem-se a faixa de $1,0.10^{-4}$ a $1,0.10^{-3} \%(\mathrm{~m} / \mathrm{v})$ de BTB.

$\mathrm{Na}$ Figura 3 observa-se que com o uso da cela delgada, o sinal correspondente a uma solução de BTB com concentração $1,0.10^{-2} \%$ atinge cerca de $40,0 \%$ da escala, enquanto que com a cela comercial, uma solução de BTB 2,5 vezes mais diluida ultrapassa consideravelmente o limite máximo da escala, comprovando-se a possibilidade de trabalhar com faixas mais amplas de concentrações empregando a cela delgada.

Como as vazões utilizadas no experimento relativo à Figura 3 são iguais, ao comparar-se a largura dos sinais exibidos, observa-se claramente que o tempo de lavagem da cela delgada é bem menor que o tempo necessário para a cela comercial; visto que a solução de BTB utilizada no experimento com a cela comercial (Figura 3B) foi 2,5 vezes mais diluida.

A variação do percurso óptico da cela delgada foi avaliada com a utilização de um espaçador de $0,8 \mathrm{~mm}$ de espessura e depois, com a adição de outro espaçador de $0,6 \mathrm{~mm}$, perfazendo um percuso óptico total de 1,4 $\mathrm{mm}$. Estes resultados são ilustrados na Figura 4, a qual mostra que a absorbância na altura máxima de pico obitda na cela com $1,4 \mathrm{~mm}$ de percurso óptico é cerca de 1,8 vezes maior do que o observado com a cela de $0,8 \mathrm{~mm}$. Este resultado indica que o sistema obedece a lei de Beer, uma vez que a razão esperada entre as absorbâncias devereria ser 1,75 tendo como base a espessura nominal dos

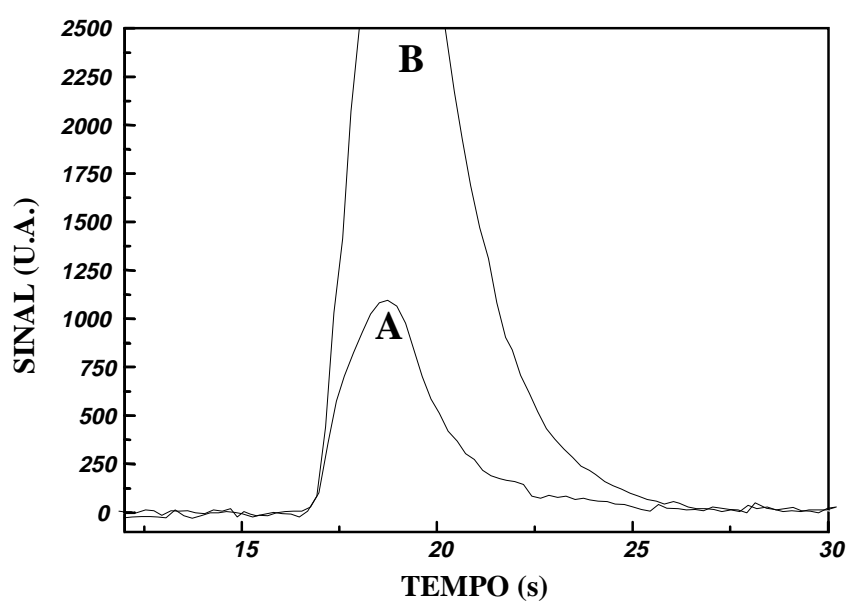

Figura 3. Comparação dos sinais obtidos com uso da cela delgada $e$ da cela comercial em " $U$ " com percurso óptico de $10 \mathrm{~mm}$. A BTB $1,0.10^{-2} \%(\mathrm{~m} / \mathrm{v})$ com a cela delgada; $B-B T B 4,0.10^{-3} \%(\mathrm{~m} /$ v) com a cela comercial. Condições Experimentais: Volume BTB = $200 \mu \mathrm{L} ;$ Vazão $=100 \mu \mathrm{L} \mathrm{s} \mathrm{s}^{-1}$; Percurso Analítico $=100 \mathrm{~cm}$. Cada variação de 0,1 unidades de absorbância corresponde a 232 unidades arbitrárias (U.A.).

espaçadores utilizados. Devido a flexibilidade do material que compõe o separador (borracha), um pequeno erro é observado.

A retenção de bolhas nas duas celas foi testado pela introdução de $10 \mu \mathrm{L}$ de ar enviado para o detetor, observandose que, enquanto a cela comercial necessitou de intervenção para retirada das bolhas para cada injeção, a cela delgada não mostrou variação significativa no sinal registrado, retornando para a linha base sem precisar de intervenção (Figura 5). Esta característica da cela delgada é de grande importância para execução de estudos de análises com fluxo segmentado, haja visto que a eliminação das bolhas ocorre de forma simples e rápida.

Tabela 2. Parâmetros analíticos das curvas obtidas ${ }^{10}$.

\begin{tabular}{ccccc}
\hline Faixas* $\left(x 10^{-4}\right)$ & Coef. Angular* & Coef. Linear & Coef.de Correlação (r) & $\mathrm{n}$ \\
\hline $1-100^{\mathrm{a}}$ & $0,214 \pm 0,004$ & $-0,3 \pm 0,2$ & 0,9997 & 11 \\
$1-10^{\mathrm{a}}$ & $0,17 \pm 0,01$ & $-0,06 \pm 0,06$ & 0,9991 & 6 \\
$1-10^{\mathrm{b}}$ & $1,23 \pm 0,01$ & $-0,04 \pm 0,06$ & 0,9999 & 6 \\
$1-10^{\mathrm{c}}$ & $0,84 \pm 0,19$ & $2,0 \pm 1,0$ & 0,993 & 5 \\
\hline
\end{tabular}

*Concentrações de BTB em \% (m/v); a = Resultados obtidos com a cela delgada; $b=$ Resultados com uso da cela comercial; $\mathrm{c}=$ Curva analítica para determinação de $\mathrm{Cr}(\mathrm{VI})$ com a cela delgada (concentrações em $\mathrm{mg} \mathrm{L}^{-1}$ ). Todos os resultados estão expressos como média de triplicatas. Condições Experimentais (a e b): Volume BTB $=200 \mu \mathrm{L}$; Vazão $=100 \mu \mathrm{L} \mathrm{s}{ }^{-1}$; Percurso Analítico $=100 \mathrm{~cm}$. 


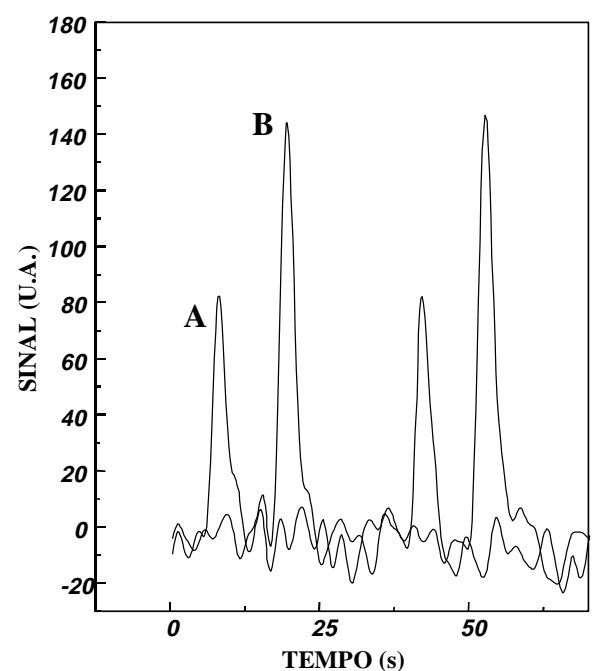

Figura 4. Variação do sinal em função do percurso óptico da cela delgada. A - 0,8 mm; B - 1,4 mm. Condições Experimentais: Concentração de $B T B=1,0.10^{-3} \%(\mathrm{~m} / \mathrm{v}) ;$ Volume $B T B=100 \mu \mathrm{L} ;$ Vazão = $100 \mu \mathrm{L} \mathrm{s}^{-1}$; Percurso Analítico $=100 \mathrm{~cm}$. Cada variação de 0,1 unidades de absorbância corresponde a 232 unidades arbitrárias (U.A.).
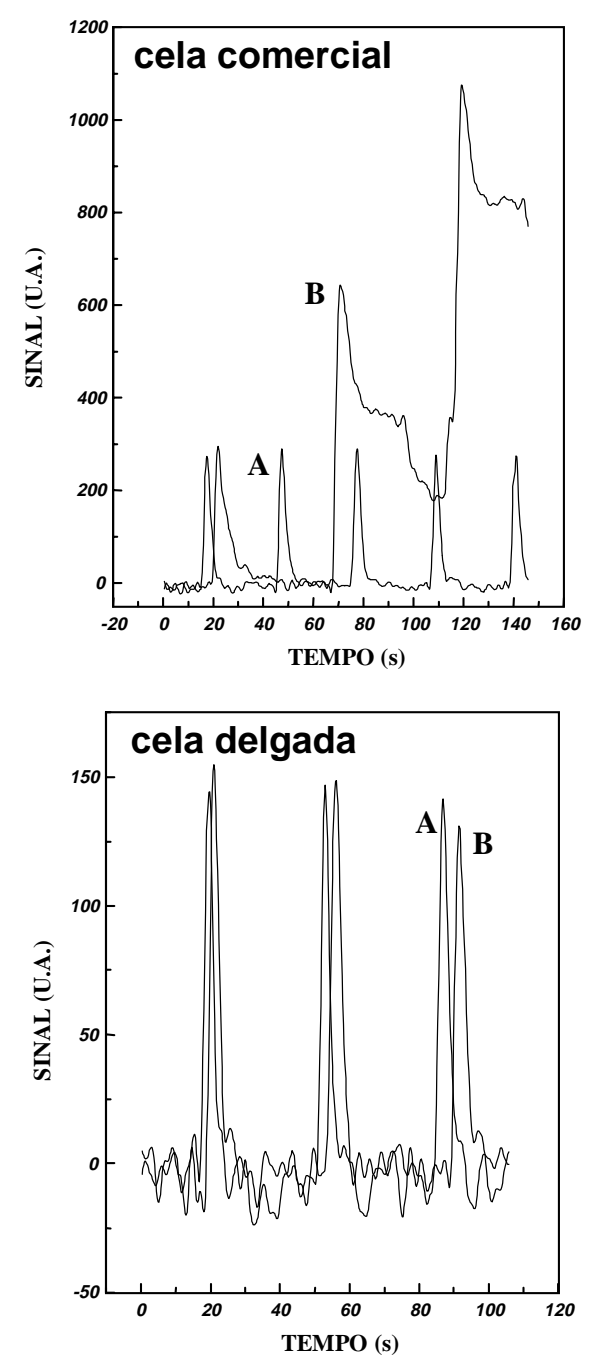

Figura 5. Influência da introdução de bolhas. A - Sem introdução de bolha; B - Com introdução de bolha. Condições Experimentais: Concentração de BTB =1,0.10-3\% $(\mathrm{m} / \mathrm{v})$; Volume BTB $=100 \mu \mathrm{L}$; Vazão $=100 \mu \mathrm{L} \mathrm{s} \mathrm{s}^{-1}$; Percurso Analítico $=100 \mathrm{~cm}$. Volume do segmento de ar $=10 \mu \mathrm{L}$. Cada variação de 0,1 unidades de absorbância corresponde a 232 unidades arbitrárias (U.A.).

\section{Análise de Amostras reais}

A curva de referência para $\mathrm{Cr}(\mathrm{VI})$ apresentou boa linearidade entre 1,0 e $10,0 \mathrm{mg} \mathrm{L}^{-1}(\mathrm{r}=0,993)$, com freqüência de análise de 80 amostras por hora conforme mostrado na Tabela 2.

A Tabela 3 exibe os resultados obtidos nas análises de amostras de aço certificados. Os resultados encontrados para as amostras foram comparados com os valores certificados com nível de confiança de $95 \%$ e não se observou evidência de erros sistemáticos ${ }^{10}$.

Tabela 3. Resultados obtidos para análise de amostras de aços certificadas.

\begin{tabular}{cccc}
\hline Matriz & Valor Certificado & Valor Observado & $\mathrm{t}_{\text {calculado }}$ \\
\hline & $(\% \mathrm{~m} / \mathrm{m})$ & $(\% \mathrm{~m} / \mathrm{m})$ & \\
\hline BCS 464 & 25,40 & $25,1 \pm 0,2$ & 2,6 \\
BCS 466 & 17,60 & $17,8 \pm 0,9$ & 0,38 \\
IPT 17A & 0,820 & $0,78 \pm 0,06$ & 1,2 \\
IPT 22 & 16,21 & $17,1 \pm 0,4$ & 3,9 \\
IPT 26 & 13,69 & $14,5 \pm 0,5$ & 2,8 \\
\hline
\end{tabular}

Os resultados são expressos como média de triplicatas para cada amostra. $\mathrm{O}$ valor de $\mathrm{t}$ tabelado ${ }^{10}$ para $\mathrm{P}=0,05$ e 2 graus de liberdade $=4,3$.

O estudo comparativo entre a cela construída e uma cela de fluxo comercial mostrou que a cela construída permite trabalhar com soluções de altas concentrações sem a perda de linearidade. Este fato possibilita trabalhar com matrizes que exibem concentrações de espécies químicas mais elevadas, reduzindo-se assim etapas de diluições, tornando bastante atraente a utilização desta cela para a monitorização de processos industriais. Certamente, nestes casos a concentração do reagente deve ser otimizada, mantendo sempre em excesso estequiométrico em toda a zona de reação para garantir a linearidade, considerando-se principalmente que o sistema de Injeção Seqüencial funciona como um sistema em fluxo de linha única, não permitindo pontos de confluência.

Os resultados obtidos mostraram-se bastante satisfatórios quando comparados com os valores certificados das amostras de aço. Como as janelas foram confeccionadas com lamínula de vidro, é possível reduzir os erros com a escolha de um vidro de melhor qualidade. Para trabalhos na região do ultravioleta, pode-se confeccionar janelas com pedaços de cubetas de quartzo quebradas ou, ainda, com lâmpadas de catodo oco danificadas.

\section{CONCLUSÕES}

A cela construída possui algumas vantagens como: simples construção, baixo custo, não retenção de bolhas, eliminação de intervenções durante as análises, variar facilmente o percurso óptico através da troca do espaçador e possuir pequeno volume interno.

Em função das características acima apresentadas, a cela permite trabalhar com concentrações mais elevadas; reduzindo de forma considerável etapas de diluição, tornando sua utilização bastante interessante na quantificação de matrizes industriais, além de possuir boa repetibilidade durante as análises.

Devido as características acima apresentadas, esta cela pode contribuir significativamente na divulgação das técnicas de fluxo em instituições de ensino técnico e superior, principalmente naquelas onde os recursos são muito parcos, além da monitorização de processos industriais e quantificação de espécies químicas em grande variedade de produtos industrializados. 


\section{AGRADECIMENTOS}

Os autores agradecem ao suporte financeiro fornecido pelo Conselho Nacional de Desenvolvimento Científico e Tecnológico (CNPq) e pela Fundação de Amparo à Pesquisa do Estado de São Paulo (FAPESP).

\section{REFERÊNCIAS}

1. Reis, B. F.; Quim. Nova 1994, 17, 228.

2. Araújo, M. C. U.; Honorato, R. S.; Santos, A. V.; Silva, E. C.; Quim. Nova 1996, 19, 86 .
3. Pasquini, C.; Raimundo Jr., I. M.; Quim. Nova 1984, 7, 24.

4. Pavon, J. L. P.; Gonzalo, E. R.; Christian, G. D.; Ruzicka, J.; Anal. Chem. 1992, 64, 923.

5. Reis, B. F.; Rocha, F. R. P.; Texeira, L. S. G.; Costa, A. C. S.; Korn, M.; Quim. Nova 2000, 23, 116.

6. Gouveia, V. J. P.; Gutz, I. G.; Rubim, J. C.; J. Eletroanal. Chem. 1994, 371, 37.

7. Ruzicka, J.; Marshall, G. D.; Anal. Chim. Acta 1990, 237, 329.

8. Costa, Max; Crit. Rev.Toxicol 1997, 27, 431.

9. Oliveira, P. C. C.; Masini, J. C.; Analyst 1998, 123, 2085.

10. Miller, J. C.; Miller, J. N.; In Statistics for Analytical Chemistry; Ellis Horwood; Chichester, 1988; cap. 2-5. 